\title{
Interaction of Plant Epicuticular Waxes and Extracellular Esterases of Curvularia eragrostidis during Infection of Digitaria sanguinalis and Festuca arundinacea by the Fungus
}

Fei Wang ${ }^{1,2}$, Peng Zhang ${ }^{1}$, Sheng Qiang ${ }^{1, *}$ and Lang-Lai Xu ${ }^{1, *}$

1 Department of Biochemistry and Molecular Biology, College of Life Sciences, Nanjing Agricultural University, Nanjing 210095, China

2 Food Quality Safety and Detection Research Center, Jiangsu Academy of Agricultural Sciences, Nanjing 210095, China

* Author to whom correspondence should be addressed. Phone: +86-025-84395773; Fax: +86-0258439667; E-Mail: xulanglai@njau.edu.cn

Received: 27 July 2006 / Accepted: 19 September 2006 / Published: 27 September 2006

\begin{abstract}
Curvularia eragrostidis, a causal agent of head blight on the weed (Digitaria sanguinalis), did not cause disease on the turfgrass Festuca arundinacea. Different extracellular esterase isoenzymes were detected in saprophytic and parasitic phases during the fungal germination. The epicuticular waxes of $D$. sanguinalis were more efficient to induce the secretion of esterases from the fungus than that of $F$. arundinacea, but were more rapidly degraded by the fungal enzymes. Component analysis indicated that the epicuticular waxes from $D$. sanguinalis were mostly composed of alcohols, with $54.3 \%$ being 9,12Octadecadien-1-ol. The main component of $F$ arundinacea waxes was alkyl compounds, with $49.8 \%$ being olefin, 9-Tricosence. More long-chained esters were found in $D$. sanguinalis waxes, which were easier to be digested than those in $F$. arundinacea waxes by extreacellular esterases of the fungus. Epicuticular waxes play a role in varying pathogenicity of $C$. eragrostidis on $D$. sanguinalis and $F$ arundinacea.
\end{abstract}

Keywords: Curvularia eragrostidis; Digitaria sanguinalis; Festuca arundinacea; wax; esterase. 


\section{Introduction}

Curvularia eragrostidis, a causal organism of head blight disease of Digitaria sanguinalis, has potential to be developed into a bio-herbicide for removal of the weed [1]. Our previous studies showed that the fungus could cause typical disease symptoms on D. sanguinalis, but was safe to many crops and lawn grasses including $F$. arundinacea, a turf grass of family Poaceae and widely-growing in China [1,2]. C. eragrostidis adheres to and breaches the cuticle of leaf, then penetrate into epidermis and mesophyll cell directly. It is known, during the fungus infection, cuticle is the first barrier, which comprises waxes and cutin. Formation of penetration peg and differentiation of appressorium by fungus on cuticle are associated with secretion of esterases. But the role of esterases in direct cuticle penetration by fungus is not well understood. [3-5].

Function of cutin and cutinase in pathogenesis has been reported in many studies [6-8]. In plants, epicuticular waxes are located on the outermost part of cuticle [9]. When microbes adhered to the epicuticular waxes, the waxes showed some important changes [10]. It has been shown that wax components acted as allelochemicals by influencing fungal development [11-13]. Changes in components of waxes depend on spatial, temporal variety and species [14-18]. But more evidences are required to elucidate the function of waxes during the plant-pathogen interactions.

Previous reports suggest that the appressorium differentiation of barley powdery mildew fungus was possibly controlled by composition of the plant waxes, which might potentially be an important element determining host or non-host relationship [19]. The main purpose of the present study is to investigate the corresponding relationship between the epicuticular waxes of two plant species and extracellular esterase of fungal conidia, and understand the role of plant epicuticular waxes and fungal extracellular esterases in host selectivity and pathogenesis.

\section{Results and Discussion}

\subsection{Results}

\subsubsection{Localization of esterase secreted by conidia}

Much mucilage secreted by conidia was visualized with the fixation (Figure 1a) and invisible without fixation process (Figure 1b). Only new hyphae, germ tubes and appressoria of germinating conidia were stained black by esterase staining reagent on leaf surface (Figure 1b) and on glass slide, however, old hypha could not be stained (Figure 1c, d).

\subsubsection{Conidia adhesion}

The count of conidia distributed by copper-grid inoculation showed no difference in the four surfaces of leaves and glass slides after inoculation (data not shown). More conidia adhered to the wax layer of $D$. sanguinalis than to that of $F$. arundinacea on leaves and wax-coated slides at both incubation times. However the numbers of adhered conidia incubated for $8 \mathrm{~h}$ in all treatments were less, but not significantly, than that for $4 \mathrm{~h}$. The conidia with longer germ tubes are rinsed out more easily (Table 1). 


\subsubsection{Extracellular esterase isoenzymes from germinating spore}

Microscopic observation demonstrated that the wash procedure neither damaged conidia nor reduced their germinating ability. There were obvious different profiles of esterases in the four extraction solutions (Figure 2). More esterase activities were observed in wash liquid of phosphate buffer supplemented with $0.1 \%$ Tween-20. Esterase isoenzyme activities were visualized by esterase staining reagent. Three esterase isoenzymes, E2, E3 and E4, were localized on the surface of ungerminated conidia of $C$. eragrostidis.

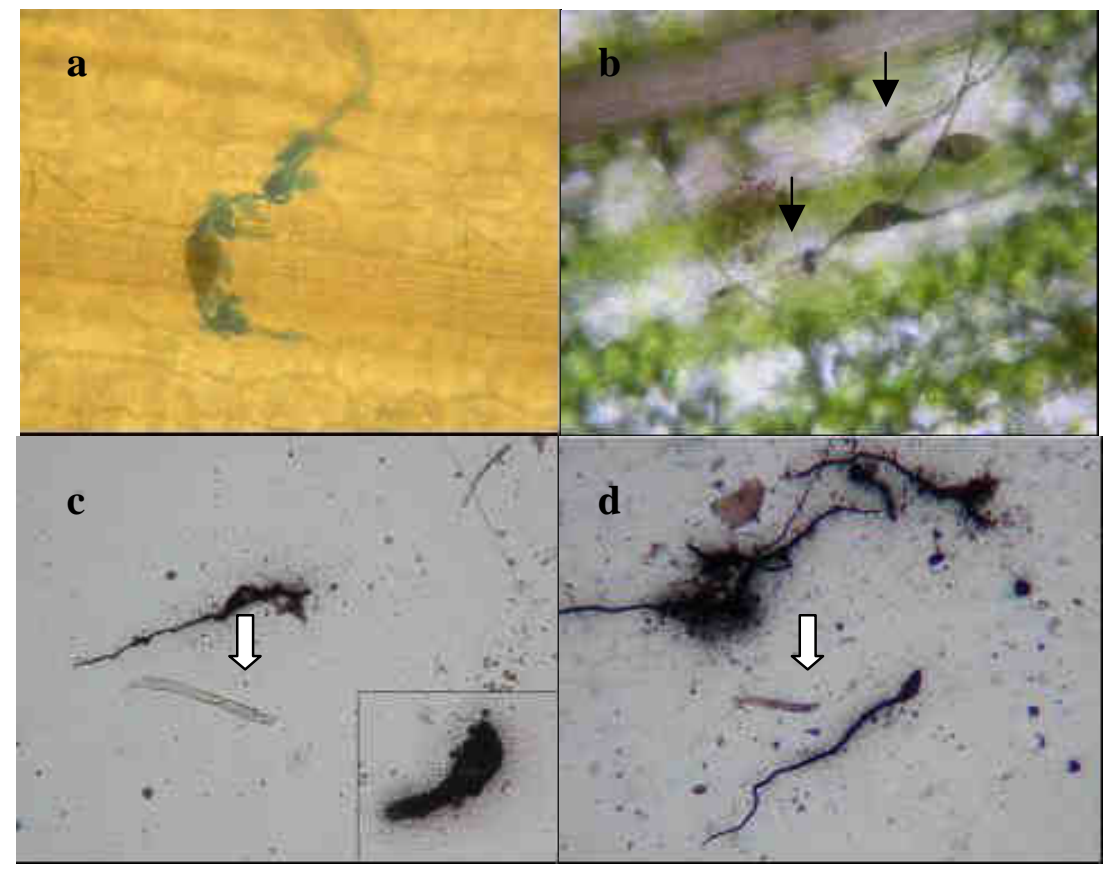

Figure 1. Esterases around the surface of germinating conidia

a. Conididium germinated on $D$. sanguinalis for $6 \mathrm{~h}$, fixed with acetic acid and ethanol (1:1), then stained with aniline blue. b. Appressoria from the germination conidia were stained by esterase stain reagent, indicated by the arrowhead. c. and d. After incubation for $4 \mathrm{~h} \mathrm{(c)} \mathrm{and} 8 \mathrm{~h}$ (d) $\square$ Conidia buried in $1 \%$ agar on glass slide were stained by esterase stain reagent. Old hypha was indicated by the white arrowhead.

Table 1. Conidial number of $C$. eragrostidis adhered to the surface of leaves of $D$. sanguinalis and $F$. arundinacea and wax layer from the two plants on glass slides

\begin{tabular}{lcc}
\hline Treatments & $4 \mathrm{~h}$ & $8 \mathrm{~h}$ \\
\hline Leaves of $D$. sanguinalis & $98.2 \mathrm{a}$ & $84.4 \mathrm{a}$ \\
Leaves of $F$. arundinacea & $75.9 \mathrm{~b}$ & $62.35 \mathrm{~b}$ \\
Wax layer of $D$. sanguinalis on glass slides & $82.4 \mathrm{ab}$ & $77.9 \mathrm{ab}$ \\
Wax layer of $F$. arundinacea on glass slides & $49.4 \mathrm{c}$ & $44.1 \mathrm{c}$ \\
\hline
\end{tabular}

Each value was the average of conidial number appeared in 20 random fields without overlap. After washing by 5 drops of water from a height of $5 \mathrm{~cm}$. Values with letter in common within a column are not statistically significant ( $p<0.05$ ), LSD test.

Different esterase secretion was checked $6 \mathrm{~h}$ after conidia germination on glass and the leaf surfaces of D. sanguinalis. E5, an esterase isoenzyme mainly appeared in the intracellular (Figure 2, lane 7), was secreted from conidia germinated on glass slides (Figure 2, lane 5). When the conidia 
germinated on D. sanguinalis leaves, E4 and E5 were not secreted, but E1 and E2 were released and showed strong activities. Meanwhile, E6 in lane 6 indicated that the leaves of $C$. eragrostidis were damaged when inoculated by the conidia for $6 \mathrm{~h}$ (Figure 2).
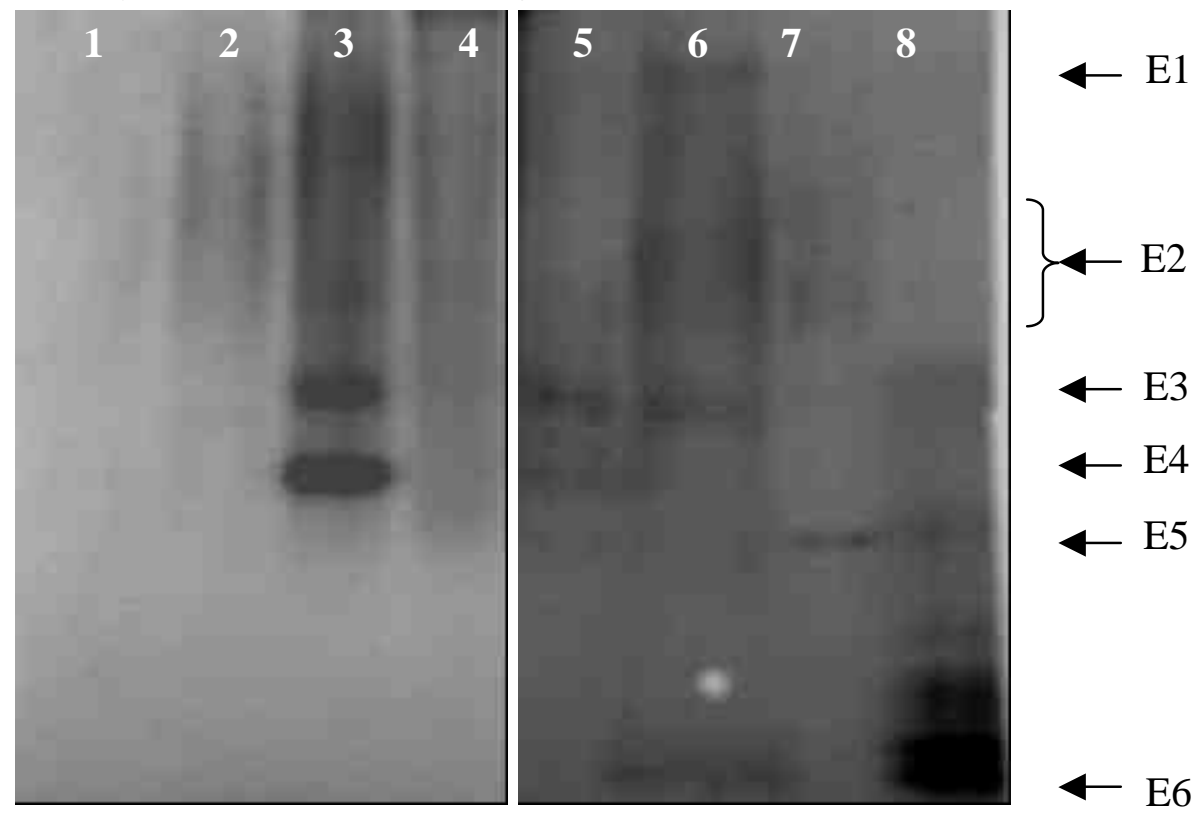

Figure 2. Analysis of esterase isoenzymes from C. eragrostidis by native polyacrylamide gel electrophoresis (PAGE, 7.5\%). Lanes:

1. Extracellular esterase was extracted with water as extracting solution.

2. $0.1 \mathrm{M}$ phosphates buffer ( $\mathrm{pH} 7.0$ ) as extracting solution.

3. Extracting solution was $0.1 \%$ Tween-20 in phosphate buffer.

4. $0.1 \%$ SDS in phosphate buffer as extracting solution.

5. Conidia germinated for $6 \mathrm{~h}$ on glass surface and extracellular esterases extracted.

6. Conidia germinated for $6 \mathrm{~h}$ on leaf surface of D. sanguinalis and extracellular esterase of conidia were collected.

7. Intracellular esterase isoenzymes of conidia germinated for $6 \mathrm{~h}$, with extracellular material removed.

8. Esterase isoenzymes from leaves of D. sanguinalis.

*1-4. Sample collected from $0.5 \mathrm{~g}$ of wet conidia. 5-7. Sample collected from $0.05 \mathrm{~g}$ of wet conidia. 8. Proteins extracted from excised leaves $(0.5 \mathrm{~g})$. The leaves had been washed with autoclaved water after $6 \mathrm{~h}$ incubation with conidia of C. eragrostidis.

\subsubsection{Induction of esterase activity by waxes}

Each culture of $C$. eragrostidis contained an extracellular p-nitrophenyl butyrate (PNB) hydrolysing activity after the conidia of the fungus were incubated for $24 \mathrm{~h}$. And esterase secretion was induced by epicuticular waxes of both plants (Figure 3). In the absence of waxes, the esterase activity was much lower. The waxes of $D$. sanguinalis showed more efficiency on inducing esterase of the fungus than that of $F$. arundinacea. In the culture with waxes of $D$. sanguinalis, esterase activity reached the highest level when the conidia were incubated for $72 \mathrm{~h}$, but showed obvious decrease on the fourth and fifth days. In the culture with waxes of $F$. arundinacea, esterase activity was less than half of that in culture with waxes of $D$. sanguinalis on the third and fourth days (Figure 3 ). As to the two aliphatic acids, 16-hydroxyhexadecanoic acid was more efficient to induce secretion of esterases from $C$. eragrostidis than palmitic acid. 


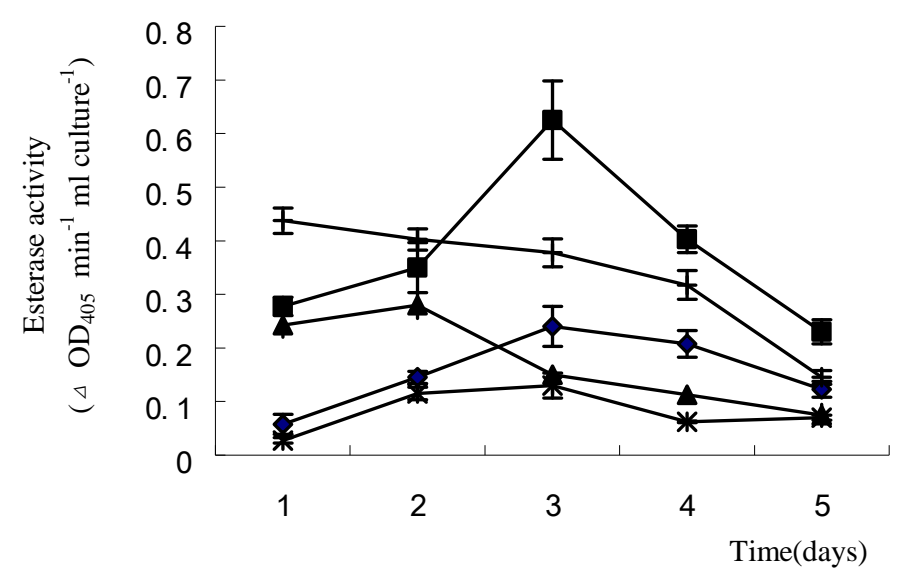

Figure 3. Induction of $C$. eragrostidis esterase activity by plant waxes in Czapek medium. $5 \mathrm{ml}$ of conidium suspension in C. eragrostidis $\left(10^{6}\right.$ conidia $\left./ \mathrm{ml}\right)$ was added to the medium and cultured for 5

d. Conidia of $C$. eragrostidis was inoculated in inorganic medium $(\square)$, mineral medium with epicuticular waxes $(20 \mathrm{mg} / 200 \mathrm{ml})$ of D. sanguinalis ( $\mathbf{a})$, mineral medium with epicuticular waxes (20 $\mathrm{mg} / 200 \mathrm{ml}$ ) of $F$. arundinacea $(\boldsymbol{\Delta})$ and mineral medium with $20 \mathrm{mg}$ of 16-hydroxyhexadecanoic acid $(+)$ and palmitic acid. $(\square)$. Results indicate the mean of three different cultures sampled in a single experiment.

\subsubsection{Degradation of two plants waxes by extracellular esterase of C. eragrostidis conidia}

Components of waxes from both plants were mainly aliphatic in nature. The most abundant component found was alcohol (9,12-Octadecadien-1-ol, $(\mathrm{Z}, \mathrm{Z})-$ ), which contained $54.3 \%$ in the epicuticular waxes of $D$. sanguinalis, and olefin (9-Tricosene, (Z)-), contained $49.8 \%$ in that from $F$. arundinacea. A few esters with phenyl were directly detected in the process and performed nearly invariable in waxes of the two plants. After the treatments by crude esterase solution from extracellular conidia of $C$. eragrostidis, 9,12-Octadecadien-1-ol, (Z, Z)- was disappeared in waxes of $D$. sanguinalis, but 9-Tricosene, $(Z)$ - was stable in waxes of $F$. arundinacea. In waxes of $D$. sanguinalis, other alcohols such as 1-Dodecanol, 1-Tridecanol et al showed much variety. The stable hydrophobic alkane contained only $9.6 \%$ of total waxes. There was a $68 \%$ decrease in the amount of waxes of $D$. sanguinalis after the hydrolysis by crude esterase solution. As for waxes of $F$. arundinacea, longchain hydrocarbons (alkane) accounted for $67 \%$ of the total epicuticular waxes. Alcohols and the esters with phenyl in the waxes of $F$. arundinacea were kept stable. There was only $3.4 \%$ decrease in the amount after the hydrolysis (Table 2).

\subsection{Discussion}

Possible components of epicuticular waxes could be alkane, alcohol, aldehyde, carboxylic acid ester (predominantly acetate) or triterpenoid [15]. It was also found that there were such components in the epicuticular waxes of the two plants. But the variety and content were greatly different in the waxes of D. sanguinalis and $F$. arundinacea according to gas chromatography-mass spectrometry (GC-MS) analysis (Table 2). Previous reports indicated that the rates of esters including straight-chain n-alkyl esters, triterpenoid esters and triacylglycerols in waxes were 7-79.5\% [20-21]. In this study, only a few phenyl esters in waxes of the two plants were detected. Possibly, many esters had been splited under high temperature condition except phenyl esters. 
Table 2. The components analysis of epicuticular waxes incubated with crude esterase solution from extracellular conidia of $C$. eragrostidis

\begin{tabular}{|c|c|c|c|c|c|}
\hline \multicolumn{3}{|l|}{ Epicuticular waxes of $D$. sanguinalis } & \multicolumn{3}{|l|}{ Epicuticular waxes of $F$. arundinaces } \\
\hline \multirow{2}{*}{ Compound } & \multicolumn{2}{|c|}{ peek area } & \multirow{2}{*}{ Compound } & \multicolumn{2}{|c|}{ peek area } \\
\hline & control & treatment & & control & treatment \\
\hline$\overline{1-D o d e c \text { anol }}$ & 32523 & -- & Tetradecane & 16088 & 15074 \\
\hline 3-tert-Butyl-4-hydroxyanisole & 53878 & 33656 & Hexadec ane & 20949 & 20521 \\
\hline Octadec ane & 29593 & 28752 & Pentadecane & 12673 & 13520 \\
\hline Ethanol, 2,2'-[oxybis (2,1-ethanediyloxy)]bis- & 49967 & 16210 & Eicosane & 37724 & 37660 \\
\hline Butylated Hydroxytoluene & 345669 & 389262 & Octadecane & 32278 & 33540 \\
\hline Diethyl Phthalate & 23170 & - - & Phenol, 2,5-bis (1,1-dimethylethyl)- & 350116 & 321242 \\
\hline 1-Tridec anol & 26275 & - - & 1,2-Benzenedic arboxylic acid, butyl 2-methylpropyl ester & 19563 & 17890 \\
\hline Octadec ane & 9160 & 11067 & Tetracosane & 10178 & - - \\
\hline 3,5-di-tert-Butyl-4-hydroxybenzaldehyde & 16654 & 15115 & 7,9-Di-tert-butyl-1-oxaspiro(4,5)deca- 6,9 -diene- 2,8 -dione & 43133 & 45123 \\
\hline 2-Dodecanol & 31091 & 17395 & 1,2-Benzenedic arboxylic acid, bis(2-methylpropyl) ester & 21836 & 24848 \\
\hline Tetradec anal & 48568 & 22587 & $4,4^{\prime}-($ Hexafluorois opropylidene) diphenol & 47295 & 26204 \\
\hline Hexadec anal & 48927 & 21578 & E-15-Heptadecenal & 60893 & 60966 \\
\hline 1,2-Benzenedic arboxylic acid, bis(2-methylpropyl) ester & 14208 & 14348 & Hexadec anamide & 16634 & 11734 \\
\hline 9,12 -Octadec adien-1-ol, (Z,Z)- & 2015689 & - - & Octadec anamide & 68974 & 43734 \\
\hline $1,4,7,10,13,16-$ Hexaoxac yclooc tadec ane & 42321 & 20081 & 1-Octadec anol & 87669 & 85592 \\
\hline Hexadec anamide & 20171 & 17173 & Nonadecane & 37237 & 30432 \\
\hline octaethylene glycol & 60132 & 23211 & Octadecanal & 189718 & 210140 \\
\hline 9-Octadec enamide, $(\mathrm{Z})$ - & 75884 & 65455 & 9-Tricosene, $(Z)-$ & 2241966 & 2251163 \\
\hline 1,2-Benzenedicarboxylic acid, mono(2-ethylhexyl) ester & 210013 & 135146 & 2-Heptacosanone & 159241 & 134575 \\
\hline 1-Docosene & 58259 & 90187 & 16-Heptadec enal & 161206 & 194897 \\
\hline 2-Heptacosanone & 154215 & - - & Tetracosane & 256913 & 263248 \\
\hline 11-Hexadecen-1-ol, ac etate, $(Z)$ - & 88563 & 76465 & 1-Hexac os anol & 431973 & 377869 \\
\hline Octadec anal & 150300 & 108426 & 2-Nonac os anone & 173009 & 160886 \\
\hline tetracosane & 110045 & 91789 & & & \\
\hline
\end{tabular}

GC-MS tests indicated epicuticular waxes from the two plants incubated with crude esterase solution from C. eragrostidis for 4 h. Heat denatured crude esterase solution used in this trial as control.

Values represent the means of two replicates. Minus sign $=$ not detected. 
In order to know the original hydrophobic components, the waxes without derivatization were also applied to GC-MS, but there are no any acids detected may due to the difficult gasification.

Adhesion to the surface of host plant is the first step of infection, so the epicuticular waxes played a barrier role in defending potential pathogens infection [22, 23]. The barrier efficiency of plant waxes may determine the possibility of a microbe to invade plants. Previous report illustrated that the surface hydrophilicity was related to attachment of fungi to leaves [24], the adhesion assay in this project also indicated the epicuticular wax layer of $F$. arundinacea was much less hydrophilic, so it could be more efficient as a barrier to the conidia of $C$. eragrostidis than that of the host plant of $D$. sanguinalis. This barrier efficiency in wax of $F$. arundinacea may be partly due to main hydrophobic component of 9Tricosene, (Z)-.

The extracellular esterases of pathogen conidia, including cutinase, were also important factors for the pathogen adhesion to the host plant. These enzymes help germinating conidia get food supply from leaf cuticle and make successful infection at last [4, 7, 8, 25, 26, 27]. But there was no previous reports about the epicuticular esterase from Curvularia spp.. Our study obviously showed that the esterases were formed as constitutive and induced enzymes on surface of the fungal conidia and invasive structures at the early phase of infection.

This study showed that different esterase isoenzymes were secreted when the conidia germinated on surface of glass and host leaves, and the activities of esterase were also different in the culture mediums containing waxes of the two plants or two long-chain fatty acids. These results indicated that the secretion of extracellular esterase of the fungus was affected by the waxes of plant. Actually it was greatly affected by different substrates. 16-hydroxyhexadecanoic acid was used as substrate of esterase in previous study [28], which showed more efficiency to induce the secretion of esterases from $C$. eragrostidis than palmitic acid. So esterase inducers for the fungus should be some specific components. 16-hydroxyhexadecanoic acid always presents in the epicuticular waxes of several plants $[21,29,30]$, but it was not detected in the waxes of $D$. sanguinalis. However, D. sanguinalis waxes were obviously more efficient on esterase induction of the fungus than that of $F$. arundinacea. The results above suggested that the inducer of esterases could be the other specific components, which might be 9,12-Octadecadien-1-ol, (Z,Z)- or its ester form in the epicuticular waxes of D. sanguinalis.

So the different results would also be appeared when two plant waxes met the esterases of conidia. The esterases degraded a majority of the waxes of D. sanguinalis. Especially 9,12-Octadecadien-1-ol, $(\mathrm{Z}, \mathrm{Z})-$, which might present as its ester form in the waxes, was disappeared after the treatment. But the hydrophobic alkyl (9-Tricosene, (Z)-) in waxes of $F$. arundinacea could not be hydrolyzed by the esterases. As a result, the hydrophobic components present in $F$. arundinacea efficiently prevented from both adhesion of conidia and the hydrolysis of esterases, and the waxes layer could form an efficient barrier against the $C$. eragrostidis's infection. Hoverver, the waxes present in D. sanguinalis could not efficiently prevent from adhesion of conidia, but stimulate the invasion of $C$. eragrostidis. So different plant epicuticular waxes and extracellular esterases of $C$. eragrostidis lead to the different results of interaction during infection of $D$. sanguinalis and $F$. arundinacea by the fungus.

\subsection{Conclusion}

When conidia of a potential fungal pathogen land on a plant surface, plant waxes may induce the production of extracellular esterases of germinating spores that digest hydrophobic esters in the wax layer [31,32]. On host plants, degradation of epicuticular waxes facilitates penetration of cell walls by 
the pathogen. On non-host plants, however, the waxes are hardly degraded and the efficiency barrier to fungal pathogen. So it's the differences of interaction between epicuticular waxes of two plant and extracellular esterases of fungus, which determined the success infection of $C$. eragrostidis to $D$. sanguinalis and the failed infection to $F$. arundinacea.

\section{Experimental Section}

\subsection{Plants and Fungal Material}

After sporulation induced by providing $48 \mathrm{~h}$ black light and at $25^{\circ} \mathrm{C}$, the conidia of C. eragrostidis were harvested from potato dextrose agar. Pre-chilled autoclaved water $\left(4^{\circ} \mathrm{C}\right)$ was used to avoid germination. The conidia were washed twice and stored at $-70{ }^{\circ} \mathrm{C}$.

Seeds of $D$. sanguinalis and $F$. arundinacea were sown in pots in greenhouse maintained at $25 \pm 2$ ${ }^{\circ} \mathrm{C}$ and 14-h Iight/10-h dark photoperiod. All seedlings for the following experiments were harvested at four-leaf stage.

\subsection{Assay of surface esterase activity}

Conidia of $C$. eragrostidis were diluted to the suspension with about 1000 conidia per $100 \mu$ L. 200 $\mu \mathrm{L}$ of conidia suspension and $2 \mathrm{ml}$ of $1 \%$ agar were mixed at about $40{ }^{\circ} \mathrm{C}$, then the mixtures was laid quickly on a thin glass and spread even film on a glass slide prior to culture at $28{ }^{\circ} \mathrm{C}$ in a humid chamber. After $6 \mathrm{~h}$ and $12 \mathrm{~h}$ of incubation, presence of esterase activity on the surface of conidia and germ tubes was assessed by esterase staining reagent $(0.03 \mathrm{~g} \alpha$ - and $\beta$-napthyl acetate, $0.06 \mathrm{~g}$ Fast Blue RR were dissolved in $2 \mathrm{ml}$ of acetone, and then mixed with $200 \mathrm{ml}$ of $0.5 \mathrm{M}$ sodium phosphate buffer, $\mathrm{pH}$ 7.5). The germinating conidia were treated with esterase staining reagent for $2 \mathrm{~h}$ with constant gentle shaking at $28{ }^{\circ} \mathrm{C}$, and then observed with the aid of light microscope [33].

\subsection{Isolation of epicuticular waxes}

Epicuticular waxes of leaves were isolated by dipping intact leaves in chloroform for $30 \mathrm{~s}$ with gentle agitation. The solvent was evaporated under reduced pressure in a rotary evaporator as suggested by Podila et al. [12]. The residues were waxes stored in dry chamber at $-20{ }^{\circ} \mathrm{C}$.

\subsection{Adhesion assay}

Chloroform solutions with $1 \mu \mathrm{g}$ waxes from the intact leaves of $D$. sanguinalis and $F$. arundinacea were respectively dried within $1 \times 1 \mathrm{~cm}^{2}$ area on glass slides surface. After the chloroform evaporated, the glasses with wax layer were kept in a humid chamber together with freshly prepared leaves of $D$. sanguinalis and $F$. arundinacea (with adaxial surface upside). Dry conidia were dusted onto the surface of leaves and wax layer on the glass slides through a copper grid of $0.8 \mathrm{~mm}$ pore size. Incubated for $4 \mathrm{~h}$ and $8 \mathrm{~h}$ at $25^{\circ} \mathrm{C}$ in darkness, the leaves and glass slides were uniformly washed by 5 drops of water from a height of $5 \mathrm{~cm}$. Immediately after washing, spores remaining on the leaf surface and wax layer on glass slides were counted under light microscope. Four repeats were carried for every treatment, and the conidial number in 5 random fields without overlap in every repeat was recorded [34]. 


\subsection{Extraction of extracellular esterases of conidia}

Extracellular esterase from $0.5 \mathrm{~g}$ of wet conidia was extracted respectively in four $20 \mathrm{ml}$ of extracting solutions [Water, $0.1 \mathrm{M}$ sodium phosphate buffer ( $\mathrm{pH}$ 7.5), the buffer supplied with Tween$20(0.1 \%$, w/v), the buffer supplied with SDS $(0.2 \%)$ and Phenylmethanesulfonyl fluoride (PMSF) $(1 \mathrm{mM})]$. After being gently shaken for $8 \mathrm{~h}$ at $4{ }^{\circ} \mathrm{C}$ in $50 \mathrm{ml}$ sterile centrifugal tubes, conidia were centrifuged (1000 rpm, $2{ }^{\circ} \mathrm{C}, 10 \mathrm{~min}$ ), and supernatant was collected to centrifuge once again. The final supernatant was filtered to ensure the absence of conidium, and the crude esterases solution was stored at $-70{ }^{\circ} \mathrm{C}[4]$.

\subsection{Esterases from germinating conidia induced by waxes and organic acids}

Wet conidia $(0.05 \mathrm{~g})$ were suspended in $1.5 \mathrm{ml}$ autoclaved water and divided into two equal portions, then one portion was distributed on surface of intact leaf (washed by autoclaved water) of $D$. sanguinalis and the other portion was distributed on glass. Incubated for $6 \mathrm{~h}$ at $25 \square$ in humid chambers, then the extracellular esterase solutions secreted by germinating fungi were collected by $0.05 \mathrm{M}$ sodium phosphate buffer ( $\mathrm{pH}$ 7.5). The solutions were centrifuged at $10000 \mathrm{rpm}$ for $10 \mathrm{~min}$, and the supernatants were treated with 4-time pre-cold acetone. The deposits were collected by centrifuging at $5000 \mathrm{rpm}$ for $5 \mathrm{~min}$, re-dissolved in $100 \mu \mathrm{l}$ of $0.1 \mathrm{M}$ sodium phosphate buffer ( $\mathrm{pH}$ 7.5), the solution was purified by centrifugation at $10000 \mathrm{rpm}$ for $10 \mathrm{~min}$, the supernatants were stored at $70{ }^{\circ} \mathrm{C}$ for esterase assay. Intracellular protein from the washed germinating conidia and $0.5 \mathrm{~g}$ of the leaf of $D$. sanguinalis (had been washed out the inoculated conidia) were extracted to use as two controls.

Wax effects on esterase induction from the germinating conidia were also investigated. $20 \mathrm{mg}$ of epicuticular waxes from both plants were re-dissolved in $2 \mathrm{ml}$ of acetone, than added to $200 \mathrm{ml}$ of liquid inorganic Czapek medium (0.6 g NaNO 3 , $0.6 \mathrm{~g} \mathrm{~K}_{2} \mathrm{HPO}_{4}, 0.2 \mathrm{~g} \mathrm{MgSO}_{4}, 0.2 \mathrm{~g} \mathrm{KCI}, 0.01 \mathrm{~g}$ $\mathrm{FeSO}_{4} \cdot 7 \mathrm{H}_{2} \mathrm{O}$ per litre) in $500 \mathrm{ml}$ conical flacks, respectively. The mediums were inoculated with $1 \mathrm{ml}$ of prepared fungal spore solution, at the cultured conditions of darkness, $25{ }^{\circ} \mathrm{C}$ and $190 \mathrm{rpm}$. The control mediums were supplemented with $2 \mathrm{ml}$ of acetone solution of 16-hydroxyhexadecanoic acid and palmitic acid, respectively. Three repeats were carried out for every treatment. $5 \mathrm{ml}$ of conidium suspension $\left(10^{6}\right.$ conidia/ml $)$ was added to every medium and cultured for $5 \mathrm{~d} .20 \mathrm{ml}$ of culture solution was sampled for enzyme assay every $24 \mathrm{~h} \mathrm{[35].}$

\subsection{Esterase assay}

Separation of esterase was carried out by running a gel of $7.5 \%$ polyacrylamide with a $4 \%$ stacking gel. The esterase activity was assayed by esterase staining reagent.

Esterase activity released from conidia to the medium was determined by the modified spectrophotometrical method of Fett et al. [36] using PNB as the substrate as described previously [37]. Reaction mixtures consisted of $980 \mu \mathrm{l}$ of Tris-HCI buffer (0.1 M, pH 8.0), $10 \mu \mathrm{l}$ of crude esterase solution and $10 \mu \mathrm{l}$ of a stock solution (16 $\mu \mathrm{l} p$-nitrophenyl butyrate resolved in $1 \mathrm{ml}$ of acetonitrile). Absorbance change due to the appearance of $p$-nitrophenyl at room temperature was monitored at 405 $\mathrm{nm}$ in $0.5 \mathrm{~cm}$ colorimetric cup. The reaction mixtures with heat denatured esterase solution were used as controls in this trial. 


\subsection{Degradation of epicuticular waxes by the extracellular esterase of conidia}

Prepared waxes $(1 \mathrm{mg})$ from leaves surface of the two plants were resolved in $100 \mu \mathrm{L}$ of acetone respectively, then mixed with $500 \mu \mathrm{L}$ of $0.05 \mathrm{M}$ sodium phosphate buffer ( $\mathrm{pH} 7.0$ ) in assay tubes, then $10 \mu \mathrm{L}$ of extracellular esterase solution extracted from spore surface was added, the tubes with heatdenatured enzyme added were used as control. After incubation at $28{ }^{\circ} \mathrm{C}$ for $4 \mathrm{~h}$ with gentle shaking, 2 $\mathrm{ml}$ of acetone was added to each tube and swirled vigorously, subsequently adequate anhydrous $\mathrm{MgSO}_{4}$ was also added. Tubes were kept in constant state without any shaking for $5 \mathrm{~h}$ at $4{ }^{\circ} \mathrm{C}$ to allow protein precipitation. After 5 hours, centrifuged at $12000 \mathrm{rpm}$ for $20 \mathrm{~min}$, then the supernatant of acetone solutions were collected and concentrated to $1 \mathrm{ml}$ under vacuum, $1 \mu \mathrm{L}$ of this solution was applied to gas chromatography with a mass detector (Agilent5973N, capillary column $30 \mathrm{~m} \times 0.25$ $\mathrm{mm} \times 0.25 \mu \mathrm{m}, 70 \mathrm{eV}, \mathrm{m} / \mathrm{z} 50-500)$ to identify the components and the variety of components among the waxes changed by extracellular esterase. The temperature chromatograph was set with an initial temperature of $100{ }^{\circ} \mathrm{C}$ for $1 \mathrm{~min}$, and then increased at $15{ }^{\circ} \mathrm{C}$ per min to $300{ }^{\circ} \mathrm{C}$, held for 5 min at 300 ${ }^{\circ} \mathrm{C}$. Peaks were identified with the aid of the NIST mass spectra library $[38,39]$.

\section{Acknowledgements}

We thank Dr. Minghua Wang (College of Plant Protection, Nanjing Agicultural University) for the valuable advice and technical support of GC-MS analysis. Research Foundation of Doctoral Program, Education Ministry of China (20050307002) and the 863 Hi-tech Research Program (2001AA246012) provided financial support for this study.

\section{References}

1. Zhu, Y.Z.; Qiang, S. Isolation, pathogenicity and safety of Curvularia eragrostidis isolate QZ2000 as a bioherbicide agent for large crabgrass (Digitaria sanguinalis). Biocontrol Sci. Techn. 2004. 14(8):769-782.

2. Zhu, Y.Z.; Qiang, S. The biological characteristics of fungus strain QZ-200 of Curvularia sp. for controlling Digitaria sanguinalis. Acta Phytopathologica Sinica 2003, 33(6) : 524 - 529.

3. Nicholson, R.L.; Yoshioka, H.; Yamaoka, N.; Kunoh, H. Preparation of the infection court by Erysiphe graminis. II. Release of esterase enzyme activity from conidia in response to a contact stimulus. Exp. Mycol. 1988, 12: 336-349.

4. Deising, H.; Nicholson, R.L.; Haug, M.; Howard, R.J.; Mendgen, K. Adhesion pad formation and the involvement of surface localized cutinase and esterases in the attachment of Uredospores to the host cuticle. Plant Cell 1992, 4: 1011-1111.

5. DeJong, J.C.; McCormack, B.J.; Smirnoff, N.; Talbot, N.J. Glycerol generates turgor in rice blast. Nature 1997, 389: 244-245.

6. Stahl, D.J.; Schafer, W. Cutinase is not required for fungal pathogenicity on pea. Plant Cell 1992,4: 621-629.

7. Yao, C.; Koëller, W. Diversity of cutinases from plant pathogenic fungi: Different cutinases are expressed during saprophytic and pathogenic stages of Alternaria brassicicola. Mol. PlantMicrobe Interact. 1995, 8, 122-130. 
8. Davies, K.A.; Delorono, I.; Foster, S.J.; LI, D.; Johnstone, K.; Ashby, A.M. Evidence for a role of cutinase in pathogenicity of Pyrenopeziza brassicae on brassicas. Physiol. Mol. Plant Pathol. 2000,57: 63-75.

9. Walton, T.J. Waxes, cutin and suberin. Methods in Plant Bioch. 1990, 4: 105-158.

10. Schonherr, J. Resistance of plant surfaces to water loss. In: Lange OL, Nobel PS, Osmond CB, Ziegler H, eds. Physiological Plant Ecology IIĐWater Relations and Carbon Assimilation I. Berlin: Springer-Verlag. 1982, 173-179.

11. Carver, T.L.W; Thomas, B.J.; Ingersonmorris, S.M.; Roderick, H.W. The role of the abaxial leaf surface waxes of Lolium spp. in resistance to Erysiphe graminis. Plant Pathol 1990, 39: 573-583.

12. Podila, G.K.; Rogers, L.M.; Kolattukudy, P.E. Chemical signals from avocado surface wax trigger germination and appressorium formation in Colletotrichum gloeosporioides. Plant Physiol 1993,103: 267-272.

13. Flaishman, M.A.; Hwang, C-S.; Kolattukudy, P.E. Involvement of protein phosphorylation in the induction of appressorium formation in Colletotrichum gloeosporioides by its host surface wax and ethylene. Physiol Mol Plant Pathol. 1995, 47: 103-117.

14. Maier, C.G.; Post-Beittenmiller, D. Epicuticular wax on leek in vitro developmental stages and seedlings under varied growth conditions. Plant Science 1998,134: 53-67.

15. Jetter, R.; Scha“ffer, S. Chemical composition of the Prunus laurocerasus leaf surface. Dynamic changes of the epicuticular wax film during leaf development. Plant Physiol. 2001,126: 17251737

16. Koch, K.; Neinhuis, C.; Ensikat, H.J.; Barthlott W. Self assembly of epicuticular waxes on living plant surfaces imaged by atomic force microscopy (AFM). J. Exp. Bot. 2004, 55: 711-718.

17. Tomaszewski, D. The wax layer and its morphological variability in four European Salix species. Flora. Jena. 2004, 199 (4): 320-326.

18. Knight, T.G.; Wallwork, M.; Sedgley, M. Leaf epicuticular wax and cuticle ultrastructure of four Eucalyptus species and their hybrids. Int. J.Plant Sci. 2004, 165(1):27-36.

19. Tsuba, M.; Katagiri, C.; Takeuchi, Y.; Takada, Y.;Yamaoka, N. Chemical factors of the leaf surface involved in the morphogenesis of Blumeria graminis. Physiol Mol Plant Pathol. 2002,60:51-57.

20. Shepherd, T.; Robertson, G.W.; Griffiths, D.W.; Birch, A.N.E. Epicuticular wax ester and triacylglycerol composition in relation to aphid infestation and resistance in red raspberry (Rubus idaeus L.). Phytochemistry 1999, 52: 1255-1267

21. Griffiths, D.W.; Robertson, G.W.; Shepherd, T.; Ramsay, G. Epicuticular waxes and volatiles from faba bean (Vicia faba) flowers. Phytochemistry 1999, 52: 607-612.

22. Jenks, M.A.; Joly, R.J.; Peters, P.J.; Rich, P.J.; Axtell, J.D.; Ashworth, E.N. Chemically induced cuticle mutation affecting epidermal conductance to water vapor and disease susceptibility in sorghum bicolor (L.) moench, Plant Physiol. 1994, 105: 1239- 1245.

23. Alcerito, T.; Brabo, F.E.; Negri, G.; Santos ,D.Y.A.C.; Meda, C.I.; Young, M.C.M.; Cha'vez, D.; Blatt, C.T.T. Folicular epicuticular wax of Arrabidea brachypoda: flavonoids and antifungal activity. Biochem. Syst. Ecol. 2002, 30: 677-683.

24. Kerstiens, G. Signalling across the divide: a wider perspective of cuticular structure-function relationships. Trends Plant Sci 1996, 1:125-129. 
25. Pascholati, S.F.; Deising, H.; Leite, B.; Anderson, D.; Nicholson, R.L. Cutinase and non-specific esterase activities in the conidial mucilage of Colletotrichum graminicola. Physiol Mol Plant Pathol. 1993, 42:37-51.

26. Sugui, J.A.; Pascholati, S.F.; Kunoh, H.; Howard, R.; Nicholson, R.L. Cutinase and non-specific esterase produced by Pestalotia malicola. Physiol. Mol. Plant Pathol. 1998, 52: 213-221.

27. Jansson, H.B.; Åkesson, H. Extracellular matrix, esterase and the phytotoxin prehelminthosporol infection of barley leaves by Bipolaris sorokiniana. European Journal of Plant Pathology, 2003, 109: 599-605

28. Osman, S.F.; Gerard, H.C.; Moreau, R.A.; Fett, W.F. Model substrates for cutinases. Chemistry and Physics of Lipids 1993, 66(3): 215-218.

29. Griffiths, D.W.; Robertson, G.W.; Shepherd, T.; Birch, A.N.E.; Gordon, S.C.; Woodford, J.A.T. A comparison of the composition of epicuticular wax from red raspberry (Rubus idaeus L.) and hawthorn (Crataegus monogyna Jacq.) flowers. Phytochemistry 2000, 55, 111-116.

30. Szafranek, B.M.; Synak, E.E. Cuticular waxes from potato (Solanum tuberosum) leaves. Phytochemistry 2006, 67: 80-90.

31. Tesch, C.; Nikolet, K.; Gnau, V.; Gotz, F.; Bormann, C. Biochemical and molecular characterization of the extracellular esterase from Streptomyces diastatochromogenes. J Bacteriol 1996, 179:1858-1865.

32. Berto, P.; Commenil, P.; Belingheri, L.; Dehorter, B. Occurrence of a lipase in spores of Alternaria brassicicola with a crucial role in the infection of cauliflower leaves. FEMS Microbiology Letter 1999, 180: 183-89.

33. Huang, T.L.; Székács, A.; Uematsu, T.; Kuwano, E.; Parkinson, A.; Hammock, B.D. Hydrolysis of carbonates, thiocarbonates, carbamates, and carboxylic esters of $\alpha$-napthol and $\beta$-napthol, and p-nitophenol by Human, rat, and mouse liver carboxylesterases. Pharm. Res. 1992, 10(5): 639648.

34. Rumbolz, J.; Kassemeyer, H-H.; Steinmetz, V.; Deising, H.B.; Mendgen, K.; Mathys, D.; Wirtz, S.; Guggenheim, R. Differentiation of infection structures of the powdery mildew fungus Uncinula necator and adhesion to the host cuticle. Canadian Journal of Botany 2000, 78(3) 409421.

35. Davies, K. A., Deloronoil, I., Foster, S. J., Lli, D., Johnstone, K. Ashby A M. Evidence for a role of cutinase in pathogenicity of Pyrenopeziza brassicae on brassicas, Physiological and Molecular Plant Pathology 2000, 57: 63-75

36. Fett, W.;F.; Gerard, H.C.; Moreau, R.A.; Osman, S.F.; Jones, L.E. Cutinase production by Streptomyces spp. Curr. Microbiol. 1992, 25: 165-171.

37. Kolattukudy, P.E.; Purdy, R.E.; Maiti, I.B. Cutinases from fungi and pollen. Methods Enzymol. 1981, 7l: 652-664.

38. Powell, G.; Maniar, S.P.; Pickett, J.A.; Hardie, J. Aphid responses to non-host epicuticular lipids. Entomol. Exp. Appl. 1999, 91: 115-123.

39. Wang, C.H.L.; Chen, C.H.K.; Gianfangna, T. Relationship between cutin monomers and tomato resistance to powdery mildew infection. Physiol Mol Plant Pathol. 2000, 57: 55-61.

(C) 2006 by MDPI (http://www.mdpi.org). Reproduction is permitted for noncommercial purposes. 